\title{
SOLE RISK PROVISIONS IN JOINT OPERATING AGREEMENTS FOR UnCONVENTIONAL OIL AND GAS DEVELOPMENT
}

\author{
RoB DESBARATS, JAY TODESCO, \\ AND KATE ROYER ${ }^{*}$
}

\begin{abstract}
This article discusses independent operations in the context of unconventional oil and gas resources. It considers how the Canadian Association of Petroleum Landmen (CAPL) and the Association of International Petroleum Negotiators (AIPN) have reacted to this. It provides a detailed analysis of the differences between the 2015 CAPL Operating Procedures and the 2014 AIPN Unconventional Resources Operating Agreement. Particular focus is given to permissible independent operations under each agreement, the timing of those independent operations, and the penalties given to a non-participating party. The article concludes by discussing the importance of drafting customized sole risk provisions in some situations, given that unconventional resource development often varies from project to project.
\end{abstract}

\section{TABLE OF CONTENTS}

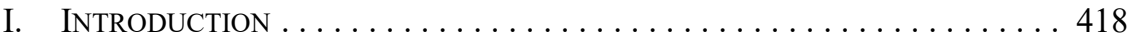

A. The Joint Venture Structure $\ldots \ldots \ldots \ldots \ldots \ldots . \ldots \ldots 18$

B. JoInt OPERAting AgreEMENTS . . . . . . . . . . . . . . . . 419

C. INDEPENDENT OPERATIONS . . . . . . . . . . . . . . . 422

II. Conventional and UnConventional Resources $\ldots \ldots \ldots \ldots \ldots 423$

A. Conventional Resource Development . . . . . . . . . . 423

B. UnCONVENTIONAL RESOURCE DEVELOPMENT . . . . . . . . . 423

C. TYPES OF OPERATIONS AND TECHNOLOGIES FOR

CONVENTIONAL AND UNCONVENTIONAL RESOURCES . . . . . . . . 427

III. ANALYSIS OF SOlE RiSK PROVISIONS . . . . . . . . . . . . . . . . . . . . 429

A. The law of Tenants in Common . . . . . . . . . . . . . . . . . . 429

B. Legal Nature of IndePendent Operations Penalties . . . . . . 431

C. Challenges With IndePEndent Operations IN THE UNCONVENTIONAL RESOURCE CONTEXT . . . . . . . . . . . . . . . . 433

D. PERMiSSIBLE INDEPENDENT OPERATIONS IN THE 2015 CAPL OPERATING PROCEDURE AND THE AIPN UROA . . . 435

E. TIMING OF INDEPENDENT OPERATIONS IN THE 2015 CAPL OPERATING PROCEDURE AND THE AIPN UROA . . . . 438

F. INDEPENDENT OPERATIONS PENALTIES AND REINSTATEMENT RIGHTS IN THE 2015 CAPL OPERATING PROCEDURE AND THE AIPN UROA . . . . . . . . . . 438

G. OTHER INDEPENDENT OPERATIONS PROVISIONS OF THE 2015 CAPL OPERATING PROCEDURE AND THE AIPN UROA

Robert Desbarats is a partner at Osler LLP, Jay Todesco is a lawyer in Calgary who practices both domestic and international oil and gas, and Kate Royer is an associate at Osler LLP. The authors would like to thank Kevin Lemke, Courtney Bohn, and Cassandra Richards for their assistance in preparing this article. The Canadian Energy Law Foundation does not necessarily endorse the contents or the opinions presented in this article. 
IV. TAILORING SOLE RISK PROVISIONS

FOR UNCONVENTIONAL RESOURCES . . . . . . . . . . . . . . . . 446

A. TEAChings From the 2015 CAPL OPERATING PROCEDURE AND THE AIPN UROA ...................... 446

B. TYPES OF UNCONVENTIONAL OPERATIONS

That May Be "Sole-Risked" . . . . . . . . . . . . . . . . . . . . 447

C. FAIR AND REASONABLE INDEPENDENT

OPERATIONS PENALTIES AND ReINSTATEMENT Rights . . . . . . . . . 450

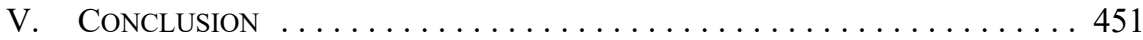

\section{INTRODUCTION}

In recent years, technologies have been developed which have made it possible to commercially develop vast quantities of petroleum and natural gas resources that were previously known to exist but which could not be commercially developed using conventional techniques. Because they are developed with unconventional techniques, these resources are known as unconventional resources.

This article discusses the contractual arrangements that are used when there are co-owners of an unconventional resource and some wish to undertake an exploration or development operation and others do not. Such operations are sometimes referred to as "independent operations," "sole risk operations," or "exclusive operations" and are referred to in this article as "Independent Operations" or "Exclusive Operations."

\section{A. The Joint Venture Structure}

It is common for two or more oil and gas companies to jointly acquire, explore, and develop petroleum and natural gas rights (usually held in Canada pursuant to a petroleum and natural gas lease or a licence, referred to in this article as a "lease," and usually held internationally under a production sharing contract, concession, licence, or other form of government grant, referred to in this article as a "Host Government Grant"). This is usually done to share risk but sometimes to share expertise, infrastructure, or other assets.

Parties that jointly own petroleum and natural gas rights can structure their relationship in a variety of ways, including by forming a corporation or partnership to own such rights. In fact, a number of unconventional resource developments in Canada have been structured as partnerships, usually for tax or governance reasons. However, by far the most common structure used in this situation is a joint venture whereby each of the co-owners (usually referred to as the "co-owners") directly owns an undivided interest in the petroleum and natural gas rights. Important reasons for using a joint venture structure are governance, ease of disposition, financing, historical practices, and, to the extent practicable, permitting an owner to conduct Independent Operations. In essence, the joint venture structure allows the co-owners to conduct separate businesses with their respective interests in the petroleum and natural gas rights, taking advantage of common aspects of those businesses and avoiding pitfalls that arise from joint ownership. This article examines the provisions found in many of such joint ventures that allow Independent Operations in the context of unconventional resource development. 
Independent Operations can be accommodated in a corporate or partnership structure and that is occasionally done, but it is complicated and inconvenient from both a tax and governance perspective. Those arrangements are not considered in this article.

There are some joint venture agreements that govern petroleum and natural gas rights that do not permit Independent Operations, such as unitization agreements entered into after a field has been delineated. However, aside from unitization arrangements, Independent Operations are usually permitted in co-ownership joint ventures for petroleum and natural gas rights.

\section{B. Joint Operating Agreements}

When the co-owners of petroleum and natural gas rights decide to use a joint venture structure, they typically enter into a joint operating agreement (JOA) to govern operations relating to the jointly owned petroleum and natural gas rights (the joint lands). A JOA is the constitution which the tenants in common that co-own the joint lands rights must adhere to for the duration of their co-ownership.

In Canada, the JOA usually consists of a main agreement, referred to as the "Head Agreement," to which a model form operating procedure is attached. The Head Agreement can modify the operating procedure but usually does not. Internationally, the JOA is usually a stand-alone, model form agreement. Whether a procedure (as in Canada) or an agreement (as is usually the case internationally), these model forms are referred to in this article as "operating procedures."

While the model form operating procedures almost always contain Independent Operations provisions, they also contain other provisions. Examples of other provisions include provisions relating to assignments and dispositions by co-owners, appointment of one co-owner (the Operator) to conduct operations on behalf of the co-owners, allocation of liabilities relating to the joint lands, and other matters. ${ }^{1}$

The Association of International Petroleum Negotiators (AIPN), the Canadian Association of Petroleum Landmen (CAPL), and the American Association of Petroleum Landmen (AAPL) are industry associations which have published model form operating procedures or operating agreements. The AIPN joint operating agreements are typically used in countries other than Canada and the United States, although they have been used for some unconventional resource projects in Canada (often because one or more of the co-owners is an international resource company that is more familiar with the AIPN than the CAPL documents). The CAPL and AAPL operating procedures are intended to be used exclusively in Canada and the US, respectively. This article considers the 2015 CAPL Operating Procedure, which is intended to be used in respect of both conventional and unconventional

Canadian Association of Petroleum Landmen, 2015 CAPL Operating Procedure (Calgary: CAPL, 2015) cls 2.06, 2.09, 3.01, 4.00, online: <landman.ca/resources/forms-store/2015-capl-operating-procedure/> [2015 CAPL Operating Procedure]; Association of International Petroleum Negotiators, Unconventional Resources Operating Agreement (Houston: AIPN, 2014) arts 3.3, 4.1, 4.2, 12.2, 13.6, online: <www. aipn.org/mcvisitors.aspx $>[A I P N$ UROA $]$. 
resources projects and the 2014 AIPN Unconventional Resources Operating Agreement, which is intended to be used in respect of unconventional resources.

CAPL and AIPN operating procedures have been used extensively for many years in relation to conventional resources. However, it was recognized by the CAPL and the AIPN that the operating procedures that were historically used for conventional resources are not completely suitable for unconventional resources. ${ }^{2}$ As a result, the AIPN UROA and the 2015 CAPL Operating Procedure were developed. It is quite clear from the extensive provisions addressing unconventional operations that the CAPL and AIPN put a great deal of effort into preparing the 2015 CAPL Operating Procedure and the AIPN UROA respectively. ${ }^{3}$

Model form operating procedures are intended to be of general application to attempt to address the needs of an entire industry. By definition, they must be generic to some extent such that it is not feasible for them to include very specialized content for unique circumstances. Thus, there are circumstances when it is appropriate for parties to add special provisions in the Head Agreement that modify or add to the operating procedure.

The CAPL and AIPN operating procedures have been created in the context of particular operating environments. It is not our intent to suggest in this article that one model form is better than the other, to suggest that the AIPN UROA should be used in Canada, or that the 2015 CAPL Operating Procedure should be used internationally. The purpose of this article is to illustrate different approaches that each uses to address how parties may want to structure their joint venture relationship with respect to Independent Operations. It is the context of that relationship and the nature and stage of development of the unconventional resource that will determine what the operating procedure should provide. ${ }^{4}$

When considering the Independent Operations provisions in the CAPL and AIPN operating procedures, it must be remembered that the AIPN operating procedures are designed to apply to very different fiscal and regulatory regimes and different size oil and gas reservoirs then those to which the CAPL operating procedures are designed to apply. An AIPN operating procedure is designed to apply to an individual Host Government Grant that covers a very large area that is expected to encompass an entire field or reservoir. A CAPL operating procedure almost always applies to one or a few individual leases covering a much

2 Jim MacLean, “CAPL Operating Procedure Term Clause: Part 2," The Negotiator (May 2014) 12, online: <landman.ca/publications/Negotiator/2014/may/may14_layout.pdf $>$.

3 In the annotations to the 2015 CAPL Operating Procedure, supra note 1, the application of the document to unconventional operations is addressed extensively. It includes special consequences of non-participation in operations, the handling of pilot projects, the use of an operating committee governance model (the AIPN UROA, supra note 1 uses an operating committee but the CAPL operating procedures do not). Instances where consideration was given to unconventional resources in provisions of the 2015 CAPL Operating Procedure include: (1) the shift to a multi-operation approval contemplated in Part I of the 2015 CAPL Operating Procedure, ibid, cl 3.01B; (2) the text and annotations on clauses $3.01 \mathrm{D}$ and $10.02 \mathrm{H}$; (3) the annotation on clause 8.02 as to why there is a separate approval required for a completion of a horizontal well and how that view may change as a project matures; (4) the annotation to clause $10.02 \mathrm{~F}$ encouraging parties to override the 3.2 kilometer restriction for horizontal well spacing at some point for unconventional projects; and (5) the first annotation on clause 12.01 that suggests that the parties consider special abandonment provisions for unconventional projects.

There are also forms of operating procedures published by other industry associations that are not considered in this article. See e.g. Oil \& Gas UK, Joint Operating Agreement (London: Oil \& Gas UK, 2008), online: <oilandgasuk.co.uk/product/joint-operating-agreement-joa-long-form-accounting-pro cedure/>; Association of International Petroleum Negotiators, JOA Australian User's Guide (2015) (Houston: AIPN, 2014), online: <www.aipn.org/mcvisitors.aspx>. 
smaller area, usually no more than a few sections of land and often less, and which rarely covers an entire reservoir or field. Moreover, international reservoirs are usually much larger than conventional reservoirs that are covered by a CAPL operating procedure, and wells in international reservoirs typically produce much more prolifically than conventional Canadian wells drilled under a CAPL operating procedure. In addition, unlike in Canada, most international oil and gas regimes provide that when a reservoir has been discovered, an appraisal plan is developed and undertaken. This is followed by a development plan being submitted to the government for approval. If approved, the reservoir is commercially developed in accordance with the approved development plan. There are no government approved appraisal or development plans in western Canada. As a consequence of these differences, exploration, appraisal, and development of conventional resources in Canada are much more likely to occur on a well-by-well basis than on a project-specific basis that involves many wells. Also, appraisal plans and development plans are important concepts in the AIPN operating procedures but are not even referred to in the 2015 CAPL Operating Procedure.

Two other distinctions between the AIPN and CAPL operating procedures that should be borne in mind when comparing the Independent Operations provisions of the CAPL and the AIPN operating procedures are:

- Under an AIPN, the penalty for non-participation in an Independent Operation is relinquishment of the Non-Consenting Party's interest in all or a portion of the area included in the Host Government Grant. ${ }^{5}$ Under a CAPL (except operation on a well required to preserve a lease), the penalty is relinquishment of production from the Independent Well (which is the well on which the operation is conducted). ${ }^{6}$

- Under a CAPL, the relinquished rights to production are automatically reinstated upon recovery of the applicable penalty out of production from the Independent Well (unless the Non-Consenting Party elects not to accept the reinstatement within 30 days of notice of recovery of the penalty). ${ }^{7}$ Under the AIPN, the Non-Consenting Party has a right to reinstate the Relinquished Rights only before the Consenting Parties undertake subsequent operations, such as appraisal, development or deepening, sidetracking, plugging back, or recompletion. ${ }^{8}$

It should also be borne in mind that Independent Operations rarely occur internationally, probably because the penalty is usually onerous and because of the "size of the prize" involved. Independent Operations, on the other hand, are very common in Canada, which means that there is much more practical experience that informs the drafting of the CAPL operating procedures than is the case with respect to AIPN operating procedures. 


\section{INDEPENDENT OPERATIONS}

The provisions of a JOA relating to independent operations should address three objectives:

1. They should balance the needs of the operator, in its capacity as such, and the other co-owners, in their capacities as non-operators;

2. they should balance the rights of the co-owners as co-owners of the joint lands; and

3. they should facilitate the efficient development of the joint lands.

A fundamental risk with the co-ownership of petroleum and natural gas rights is the possibility of disagreement among the co-owners on whether, when, and how the joint lands will be explored, appraised, and developed. To deal with this concern, many JOAs contain Independent Operations provisions to balance the rights of co-owners who wish to conduct an Independent Operation with the rights of co-owners who are unable or unwilling to participate in the operation, whether because of lack of funds, disagreement on the merits, or risk of the proposed operation - or for other reasons.

The rationale for Independent Operations provisions is that, to the extent practicable

- $\quad$ no co-owner should be prevented from conducting operations it wishes to perform; and

- no co-owner should be obligated to participate in operations that it has not approved.

To some extent, Independent Operations provisions are contentious in the sense that they can be seen as contrary to the overarching principles of a JOA, which are to jointly develop a property and to share project risks in doing so. Particularly in the unconventional context, because of the variable economic and productive profile of an unconventional resource project, there is some debate in the petroleum and natural gas industry as to whether any Independent Operations should be allowed as they may operate to the detriment of the wider interests of the project. Nonetheless, many JOAs for unconventional resources permit Independent Operations to some extent.

This article is divided into three parts. The first considers the differences between conventional and unconventional resource development operations. The second is an analysis of the Independent Operations provisions of the 2015 CAPL Operating Procedure and the AIPN UROA. The third is a discussion of Independent Operations provisions that could be included in a Head Agreement to better navigate some of the challenges presented by Independent Operations. 


\section{Conventional AND UnCONVEntional ResourCeS}

\section{A. Conventional Resource Development}

Development of conventional petroleum and natural gas resources is commonly described as having four stages:

1. Exploration - operations to discover a naturally occurring accumulation (a "reservoir") of crude oil, natural gas, or similar hydrocarbons ("petroleum substances") that were not previously known to exist with certainty. This may include the drilling of wells and seismic or other geophysical or geological studies and analysis;

2. Appraisal - drilling of wells and (sometimes) conducting seismic studies to determine whether the accumulation of petroleum substances, whose existence as reservoir was established in the exploration stage, is present in commercial quantities and to ascertain the nature and extent of the reservoir;

3. Development - the drilling of wells and the installation of infrastructure appropriate for the efficient commercial production of the petroleum substances from an appraised reservoir; and

4. Production - the production of petroleum substances on a commercial basis until the production from the reservoir is no longer commercially viable. ${ }^{9}$

Once production from a conventional reservoir commences, the inherent pressure within the reservoir usually leads to the free flow of petroleum substances from the reservoir to the surface. Production is sometimes enhanced by the use of pumps where the reservoir pressure is insufficient to bring commercial quantities of petroleum substances to the surface. Peter Roberts notes that "flow rates from that well will ordinarily be characterized by a steady ramp-up and a smooth plateau production profile, before an eventual decline phase and the permanent cessation of gas production."10 In conventional petroleum development, the exploration, appraisal, and development stages are quite distinct from one another, and the risk profile for the project decreases in a linear fashion with each stage in the life cycle. ${ }^{11}$

\section{B. UnCONVENTIONAL RESOURCE DEVELOPMENT}

The AIPN UROA defines "Unconventional Resource" as "an accumulation of hydrocarbons with low permeability and porosity that consequently is difficult to exploit commercially without unconventional methods, such as drilling horizontal wells and/or hydraulic fracturing." 12 Unconventional resources can include oil sands, extra-heavy oil,

Peter Roberts, “Joint Venture Agreements' Role In The Shale Gas Boom,” Law360 (11 June 2014), online: $<$ www.law360.com/articles/545205/joint-venture-agreements-role-in-the-shale-gas-boom $>$. Ibid.

Fenner L Stewart \& Anthony G Cioni, "Unconventional Risk Allocation: Managing the Life Cycle of Shale Projects," The Negotiator (October 2015) 2 at 4, online: <landman.ca/wp/wp-content/uploads/ 2015/10/Oct2015_layout.pdf>.

AIPN UROA, supra note 1, art 1.1. 
coalbed methane, and deep water reservoirs. This article focuses on unconventional projects such as shale gas and tight oil, where oil and natural gas is produced using a combination of horizontal drilling (usually from a drilling pad) and fracturing or "fracking." 13 Such unconventional resource projects can be small in scale, only occupying a thousand acres of land, or they can constitute major cascading development undertakings covering thousands of acres.

Unconventional resource development differs from the four phases of conventional resource development in a number of ways. One fundamental difference is that there is not a concept of a discovery or appraisal in the same sense as with respect to a conventional resource. This is because the existence of an unconventional resource is usually known before any wells are drilled. However, the drilling of one or more wells or other geological tests may be required to determine whether the reservoir can be exploited economically and, if so, how best to exploit it. Another fundamental difference is that the methods used to exploit an unconventional reservoir often change over the course of the exploitation of the reservoir. This is because better techniques to exploit the reservoir are developed in the course of exploitation and because the presence of "sweet spots" in the reservoir, which are more prolific than other portions of the reservoir, are often difficult to predict.

Wood Mackenzie has identified four phases for unconventional projects:

1. Concept - a technical strategy is developed to maximize the potential profitability of the development based on known geological characteristics and anticipated economics;

2. Pilot - the strategy developed in the concept phase is tested by drilling a limited number of wells and performing various fracking operations;

3. Ramp-Up - if the pilot phase is successful, additional wells are drilled to assess the project's operational and economic viability; and

4. Exploit - unlike the production phase of a conventional development, the exploit phase is a constantly evolving operation where the length and spacing of wells, the nature of the fracking program (including the number of frack stages, nature of the frack fluid, and type of proppant), and other operating techniques are continuously modified to take into account experience obtained in the development of the project. The exploit phase may evolve continuously for years through a trial and error approach as the resource is developed. ${ }^{14}$

13 Fracking is a technique used to stimulate production of petroleum substances after a well has been drilled. It consists of injecting a mixture of water, sand, and chemical additives through the wellbore into the objective formation under high but controlled pressure. The process is designed to create small cracks within the formation. The width of the fractures and the distance that each of the fractures extends into the formation depend on the rate, pressure, and timing of fluid injection. Once the fracking occurs, proppant, which is usually sand or some other inert material, is carried into the newly formed fractures to keep them open after the pressure is released. Previously trapped petroleum substances are then able to flow through the new fractures.

$14 \quad$ Neal Anderson \& Preston Cody, Shale vs. Big Exploration: What Sort of Risks Are You Taking? (Houston: Wood Mackenzie Consulting, 2012) at 4, online: <www.woodmac.com/content/portal/public/ consulting/WM\%20Upstream\%20Perspective\%20-\%20Shale-v-Big\%20Exploration\%20August $\% 20$ 2012.pdf $>$. 
These phases are not universal in application and each unconventional development has to be customized based on a number of factors, including reservoir quality and size, economics, time constraints, development size, and the underlying fiscal regime. Furthermore, unlike the four phases of conventional development, which are quite distinct from each other, the phases of unconventional development tend to be overlapping as an iterative approach is often adopted given changes in how the resource performs over time.

The risk profile for unconventional resource development is more complicated than that of a conventional project. Unconventional resource projects are usually capital intensive with significant investment in the early stages. Unconventional wells are usually characterized by steep initial production declines (60 to 80 percent in the first 12 months of production) with long, flat production thereafter. The developers of the resource are usually on a "drilling treadmill" to offset production declines and to maintain an economic production level.

Unconventional reservoirs are usually developed by wells with a production profile that declines more rapidly than wells drilled into a conventional resource, since wells drilled into an unconventional resource often have a much smaller drainage area. Development costs are much higher for an unconventional resource than a conventional resource due to the greater use of expensive horizontal wells and multi-stage fracking and a much larger land base is generally required for the commercial development of an unconventional resource as compared to a conventional resource. Access to the large land area required for development of an unconventional resource can be impacted by several factors including remoteness, the location of rivers and lakes, seasonal restrictions and infrastructure (for example, ice bridges), lack of infrastructure, and First Nations issues.

Another important difference between conventional and unconventional resources is that the former are usually developed on a well-by-well basis while the latter are usually developed by one or more continuous multi-well drilling programs. In an unconventional resource project, no single well is a huge profit centre or a huge risk. Instead, profitability of an unconventional resource project comes from drilling a large number of modestly profitable, low-risk wells using common infrastructure, multi-well drilling pads, and multiwell drilling programs to reduce costs. This approach has been referred to as a manufacturing process. It relies less on geological prowess resulting in discovery of a prolific reservoir, but instead on drilling and fracking technologies, operational efficiencies, and economies of scale.

Since multiple wells are required and since, unlike most conventional resources, the results from one well will usually not significantly affect the risk of subsequent nearby wells, it is often more efficient to develop an unconventional reservoir with continuous, multi-well drilling programs in which the wells are drilled without waiting to assess the results of previous wells in the program. Moreover, unconventional resources are usually developed with horizontal wells, ${ }^{15}$ which must be engineered on the assumption that a completion

15 Horizontal wells are initially drilled vertically and then are "kicked-off" on the horizontal axis into the geological horizon that is being explored or developed by the well. Horizontal wells access more of the producing formation than vertical wells because a horizontal well is drilled along the length of the formation while a vertical well is drilled through it, which often results in horizontal wells producing more petroleum substances from the reservoir than the same number of vertical wells and producing them more quickly. However, horizontal wells are much more expensive than vertical wells. The 
program will ultimately be conducted, with the result that there is no casing point election (a casing point election is a decision to complete or abandon a well that is made after the well has been drilled and tested).

A further distinction between conventional and unconventional resource development arises in the context of drainage and well spacing. Because of the porosity and permeability of the reservoir, the area drained by a vertical well drilled into a conventional resource will usually drain a predictable area around the well. In Alberta, this is normally a 160 acre quarter section for an oil well and a 640 acre section for a gas well. However, a horizontal well drilled in an unconventional resource with poor porosity and permeability will usually drain only a limited area around the portion of the horizontal leg of the well that is exposed to the producing formation by perforation. This means that the spacing of the wells in a conventional resource will be uniform, which, in Canada, are established by government regulation (for example, in Alberta, usually one well per quarter section for an oil reservoir and one well per section for a gas reservoir $\left.{ }^{16}\right)$. However, it will not be uniform in the case of an unconventional resource. Moreover, many more wells will be drilled to exploit an unconventional resource than a conventional resource and the wells will be closer to each other. The underlying land tenure documents and spacing units often do not address this difference.

In addition to geological and technical complexities, unconventional resource development requires a service sector that can support a high volume of drilling and "fracking" operations. Fracking operations require a significant volume of water and proppant that must be accessed, transported, and stored until required. Pipeline infrastructure, a qualified and skilled work force, and competition for services, as well as the applicable fiscal regime and commodity prices will all have an impact on unconventional resource development. Compounding each of these is the extended time frame in which an unconventional resource development is likely to be conducted and the possibility that any of these factors will change over time. The result is a risk profile vastly different than a conventional well.

One concern with multi-stage fracking is the possibility that the fracking of a well may adversely affect neighbouring wells. Fracking causes a physical disturbance or tremor that could affect a neighbouring horizontal wellbore and could impair its capacity to produce petroleum substances. This is a serious enough issue that, sometimes, when a horizontal well is to be drilled, to avoid problems with a neighbouring well, the wellbore of the neighbouring well is filled with water to protect it with the intention that the water will be removed after the new well is fracked. Because of the possibility of such damage, it is often prudent to develop an unconventional reservoir with incremental drilling. Incremental drilling is where each well is drilled in close proximity to the previous well rather than attempting to delineate the boundaries of the reservoir and then exploiting it by infill drilling. The latter could entail greater risk to existing wellbores.

improvements in the quantity and rates of production may not justify the additional cost if the reservoir has sufficient porosity and permeability that it can be effectively drained by vertical wells. Horizontal wells are sometimes also used in conventional operations.

Oil and Gas Conservation Rules, Alta Reg 151/1971, s 4.10(3). 


\section{TYPES OF OPERATIONS AND TECHNOLOGIES FOR CONVENTIONAL AND UNCONVENTIONAL RESOURCES}

The discovery and development of a reservoir can include the following operations:

\section{GeOPHYSICAL, GeOCHEMICAL, AND GeOlogicAl StUdies}

Acquisition of geophysical, geochemical, and geological data ("G \& G Data") by operations other than drilling wells is often undertaken with the objective of acquiring information about the existence or nature of a reservoir. The most common of these activities is the acquisition and analysis of seismic data. ${ }^{17}$

\section{EXPLORATORY DRILLING}

An exploratory well is commonly defined as a well whose purpose at the time of drilling is to explore for (that is, discover) an accumulation of petroleum substances, whose existence had not previously been proven by drilling. ${ }^{18}$ In a CAPL operating procedure, the term "Exploratory Well" is defined as a well that is not a Development Well. ${ }^{19} \mathrm{~A}$ "Development Well" is defined as a well that is within 3.2 kilometers of another well that is or has been capable of producing from a formation above the deepest formation in the first mentioned well. ${ }^{20}$ In conventional resource development, an exploratory well, if successful, is usually eventually completed for the taking of production. In unconventional resource development operations, the drilling of an exploratory well is usually to acquire information in order to establish the nature or extent of a resource whose existence was previously known to exist from geological data. It may or may not be intended that the well will ever be completed and produced. An exploratory well drilled on an unconventional resource may be a vertical well even though the resource will eventually be developed with horizontal wells.

\section{Multi-Stage Fracking}

Techniques for fracking horizontal wells at multiple intervals in a series of consecutive operations, known as multi-stage fracking, which optimize the fracking of lengthy horizontal well legs, have been developed in recent years. The fracking operation occurs once drilling and perforating operations are completed. Vertical wells have been fracked for at least 50 years, but multi-stage fracking in horizontal wells is a relatively recent development that is

17 Seismic surveys are used to produce detailed images of the various rock types and their subsurface location. Sound waves are bounced off of underground rock formations and the waves that reflect back to the surface are captured by recording sensors. Analyzing the time the waves take to return to the recording sensors provides information about rock types, gases, and fluids within the rock formations: Petroleum Exploration \& Production Association of New Zealand, "Seismic Surveys: Exploring What Lies Beneath," Seismic Survey, online: <www.seismicsurvey.co.nz>.

18 These are the authors' personal experiences. See AIPN UROA, supra note 1, art 1.1.

2015 CAPL Operating Procedure, supra note 1, cl 1.01.

The definition of "Development Well" in the 2015 CAPL Operating Procedure, ibid provides that this is "measured from the coordinates where the respective wells penetrate the top of that geological formation, or, for any such well that is a Horizontal Well, the nearest points of each well in the applicable formation, while treating any applicable Horizontal Leg as a single well for this purpose" (ibid, $\mathrm{cl}$ 1.01). The authors believe (without confirmation from the CAPL) that the 3.2 kilometer test is based on the assumption that, in most cases, a vertical well that is 3.2 kilometers from any existing wellbore is far enough from any vertical wellbore that it has the same risk as a vertical well that is not drilled into a previously established reservoir. 
continuously evolving. It is the combined use of horizontal wells and multi-stage fracking that has resulted in the development of shale and other tight formations that could not previously be developed economically. Horizontal well legs can be more than 3,000 meters long. Multi-stage fracking programs can comprise an almost unlimited number of stages and use huge quantities of water and tons of sand proppant.

\section{Pilot PRojects}

A pilot project is "the set of operations, activities, wells and facilities needed to evaluate the unconventional exploitation methodologies to be used to exploit specified sub-area(s) in an unconventional resource in order to determine the commercial viability of a large scale exploitation of such unconventional resource," ${ }^{21}$ and which forms part of the broader unconventional project life cycle. A pilot project is usually not a commercial project but, rather, a set of operations designed to determine whether and, usually, how a commercial project can be implemented.

The exploration and appraisal of an unconventional resource will not always include all of the foregoing activities and may not include any of them. In many cases there is no pilot project. Pilot projects are not contemplated by the CAPL operating procedures, although the annotations to the 2015 CAPL Operating Procedure note that parties may want to consider special handling of a pilot project in the Head Agreement. ${ }^{22}$ Pilot projects are mentioned in the AIPN UROA, but are not discussed in detail. Pilot projects are not referred to in the 2012 version of the AIPN operating procedure, which is the most recent version of the AIPN operating procedure designed for conventional resources. ${ }^{23}$

\section{DRILLING APPRAISAL WELLS}

After the existence of the reservoir is established by the drilling of one or more exploratory wells, the extent of the reservoir is established by the drilling of wells known as appraisal wells. Appraisal wells could be vertical wells even if the reservoir will be developed by horizontal drilling. Appraisal wells and appraisal plans are not referred to in the CAPL operating procedures, which only consider exploratory wells and development wells, or in leases used in western Canada. Appraisal plans and appraisal wells are important features of Host Government Grants, the AIPN UROA, and other AIPN operating procedures.

\section{DRILLING DEVELOPMENT WELLS}

After the existence of a reservoir has been confirmed and it has been established that it contains quantities of petroleum substances that can be exploited commercially, the reservoir

$21 \quad$ Roderick Perez, "Seismic Brittleness Index Volume Estimation From Well Logs in Unconventional Reservoirs (Part II): Brittleness Definitions Review” (10 July 2014), DI Blog (blog), online: <info. drillinginfo.com/brittleness-definitions-review>; United States, US Energy Information Administration, "Schematic Geology of Natural Gas Resources"'(Washington DC: EIA, 2010), online: <www.eia.gov/ oil_gas/natural_gas/special/ngresources/ngresources.html>.

222015 CAPL Operating Procedure, supra note 1 at Section I, Part F of Annotations - Addendum.

23 Association of International Petroleum Negotiators, Joint Operating Agreement (Houston: AIPN, 2012), online: < aipn.org/mcvisitors.aspx $>$. 
is drained by wells known as development wells. These are less risky than exploratory and appraisal wells because the reservoir has been proven to exist and, if necessary, appraised.

\section{CONSTRUCTING INFRASTRUCTURE}

In the development phase, production infrastructure, such as oil batteries, gas compressors, processing plants, storage tanks, and pipelines that are necessary to market the petroleum substances produced from the wells, is constructed.

\section{DeVEloping Other TECHNOLOGIES}

Other new technologies have also enhanced the commerciality of the development of unconventional resources, such as the use of multi-well drilling pads. A multi-well drilling pad is simply a surface location used to drill multiple wells. The pad itself can be a designated surface area upon which operations are conducted or an elevated platform that enhances continuous drilling operations. Being able to consolidate all drilling operations and some production facilities on one pad allows for significant cost savings, thereby adding to the economic viability of the resource. ${ }^{24}$ Drilling pads can be used in both conventional and unconventional resource development.

Another relatively new technology is "Stompers for Walking" or "Walkers" which can move a rig without the requirement to dismantle the rig and remove the drill pipe. Relocating a rig can therefore be achieved within hours as opposed to days. ${ }^{25}$

\section{Analysis of Sole Risk Provisions}

\section{A. The LaW of Tenants in Common}

Although commonly referred to as joint owners, parties holding interests in real property with no right of survivorship are actually characterized under common law as tenants in common. This is acknowledged in the 2015 CAPL Operating Procedure. ${ }^{26}$ Tenancy in common is the concurrent, simultaneous ownership of real property by two or more parties. Tenants in common may hold unequal interests. All tenants in common hold an individual, undivided ownership interest in the property. ${ }^{27}$

English and Canadian law recognize four basic principles with respect to co-ownership of property: (1) each co-owner is entitled to possession of the common property and the use and enjoyment thereof; (2) no co-owner can oust another co-owner; (3) a co-owner is not

Victor Bunk \& Richard Avant, "Simultaneous Operations: The Key to Speed and Efficiency for Unconventional Oil and Gas" (Alvarez \& Marsal Holdings, 2011), online: <www.alvarezand marsal.com/sites/default/files/sidebar-callouts/2.pdf>; Sudakshina Bhattacharjee, "Cost Reduction: Understanding The Economics of Multi-Well Pad Drilling," Drilling Point (18 December 2014), online: $<$ www.drillingpoint.com/p2847/cost-reduction-understanding-the-economics-of-multi-well-paddrilling/>.

25 United States, US Energy Information Administration, Trends in U.S. Oil and Natural Gas Upstream Costs, (Washington, DC: EIA, 2016) at 14, online: <https://www.eia.gov/analysis/studies/drilling/pdf/ upstream.pdf $>$.

262015 CAPL Operating Procedure, supra note 1, cl 1.05(A).

27 Common ownership only arises when the interest is undivided. 
entitled to commit destructive waste with respect to the common property; and (4) if one coowner receives more than its share, it is under a duty to account to the other co-owners. ${ }^{28}$

Since tenants in common have unity of possession, each is entitled to full occupation and legitimate use of the property. Thus, one co-owner cannot stop the other from such use or occupation, unless the use or occupation amounts to destruction of the property. The law of tenants in common provides that a co-owner of property may bring an action to account against another co-owner where that other co-owner has received more than its share of profits or income from the joint property. ${ }^{29}$ However, a co-owner does not receive more than its fair share of profits or income where that extra share was earned through its efforts or expense. ${ }^{30}$ As explained in the case of Rees $v$. Rees, ${ }^{31}$ a co-owner will not be called to account for income that is generated by his own labour, such as farming the land and selling crops. A co-owner can, however, be called to account for revenue obtained from selling a natural material which diminishes the value of the land itself. Where a co-owner has received in excess of its share of profits or income, it can claim for the expenses incurred to earn such income. $^{32}$

What constitutes "destructive waste" can be a critical issue. In the Canadian case of Dougall v. Foster, a co-owner was restrained from excavating soil from the common property in order to manufacture bricks. ${ }^{33}$ In Goodenow v. Farquhar, it was held that a coowner was not allowed to quarry stone from the common property even though the land was useless for any other purpose. ${ }^{34}$ In Broadfood v. Bush, an Ontario court granted an injunction preventing the cutting of timber by a co-owner on joint lands which were only valuable for their timber, and not as farmland. ${ }^{35}$ The injunction was granted on the basis that cutting the timber amounted to a destruction of the property and was not a legitimate mode of enjoyment of the right of occupation of a co-owner. In examining the concept of destructive waste described in each of these cases, it is clear that one must focus on the overall impact of the activity on the common property itself.

Courts in many petroleum producing jurisdictions in the US, including Oklahoma and Texas, have held that a co-owner is not committing destructive waste by producing petroleum. ${ }^{36}$ The rationale is generally premised on the fact that minerals, by their nature, are enjoyed and become valuable only through extraction. Therefore, such extraction should not constitute waste. Furthermore, since each co-owner is entitled to enjoy the common lands, any other result would deny a co-owner the enjoyment of the minerals. The American courts also emphasize that since petroleum and natural gas are "fugitive substances" and may be

\footnotetext{
28 Martin M Olisa, "Legal Problems Arising Out of Co-Ownership of Oil and Gas Leasehold Estate and Facilities" (1970) 8:2 Alta L Rev 177 at 178-79.

Law of Property Act, RSA 2000, c L-7, s 17(2)(c).

Field $v$ Field (1910), 8 ELR 374 (PEI Ch).

Rees $v$ Rees, [1931] SASR 78 (Sup Ct).

Marriott v Franklin (1993), 60 SASR 457 (Sup Ct).

Dougall v Foster (1853), 4 Gr 319 (Ont).

Goodenow v Farquhar (1873), 19 Gr 614 (Ont).

Broadfoot v Bush (1859), 7 Gr 518 (Ont).

Prairie Oil \& Gas Co v Allen, 2 F (2d) 566 (8th Cir 1924); McCord v Oakland Quicksilver Mining Co, 27 P 863 (Cal 1883); New Domain Oil \& Gas Co v McKinney, 221 SW 245 (Ky Ct App 1920); Burnham v Hardy Oil Co, 195 SW 1139 (Tex 1917) [Burnham]; Compton v People's Gas Co, 89 P 1039 (Kan 1907); Silver King Coalition Mines Co v Silver King Consol Mining Co, 204 F 166, (8th Cir 1913).
} 
drained by a well on adjoining land, they must be promptly taken by the owners thereof and a non-consenting owner should not be allowed to impede this prompt taking. ${ }^{37}$

The law of tenants in common that would otherwise apply as among the tenants in common can be varied by contract.

The law of tenants in common applies to the co-ownership of petroleum and natural gas rights. Co-owners of petroleum and natural gas rights should expressly address their respective rights and obligations through contract to avoid unexpected consequences. In Canada, although the law is not settled, it is possible that a tenant in common would not be allowed to produce petroleum substances from the co-owned lands and may be subject to injunctive relief if it attempts to do so without the consent of the other tenants in common. Even if allowed to conduct such operations, a tenant in common that undertakes an Independent Operation may be subject to an action to account by other tenants in common, since the production was taken from the common lands. There are two measures for this accounting: (1) the tenant in common that takes the production might have to pay over a portion of the profits, accounting for the costs it incurred; or (2) the tenant in common that takes production might have to compensate the other tenants in common for the reduction in the value of the land.

Typical Independent Operations provisions are not, therefore, a codification of the common law relating to tenants in common. Rather, they modify the co-owners' rights and obligations in relation to common property, while at the same time seeking to maintain some of the common law principles of co-ownership. An important reason for including Independent Operations provisions in JOAs is to supersede the law of tenants in common by permitting co-owners to circumvent difficulties and uncertainties imposed by the law of tenants in common. ${ }^{38}$

\section{B. Legal Nature of Independent Operations Penalties}

A JOA will almost always provide that a co-owner who elects not to participate in an Independent Operation (called a Non-Participating Party in the 2015 CAPL Operating Procedure $^{39}$ and a Non-Consenting Party in the AIPN UROA ${ }^{40}$ and referred to by both names in this article) will suffer consequences (referred to in this article as an Independent Operation Penalty) as a result of not participating in the operation. The Independent Operation Penalty under a CAPL operating procedure is a relinquishment of rights to production (except in the case of a well that preserves title (a Title Preserving Well)), and to information from the operation. ${ }^{41}$ Under the AIPN UROA, the penalty is a relinquishment of rights in the petroleum and natural gas lease or other government grant (or a specific sub-area to which the Independent Operation relates). ${ }^{42}$ Usually, the Non-Participating Party has rights (called Reinstatement Rights in this article) to reinstate the relinquished rights. Under the 
2015 CAPL Operating Procedure, the Reinstatement Rights arise when the costs of the Independent Operation plus a premium (called Reinstatement Premium in this article) are recovered from the Independent Operation by the owners who participated in it (called the Participating Parties in the 2015 CAPL Operating Procedure and the Consenting Parties in the AIPN UROA and referred to by both names in this article). ${ }^{43}$ Under the AIPN UROA, the Reinstatement Rights are triggered by a decision by the Consenting Party to appraise or develop the Exclusive Area for the well that is the subject of the Independent Operation, or to deepen, complete, sidetrack, plug back, or recomplete the well. ${ }^{44}$ The reinstatement rights terminate 30 or 60 days (or 48 hours in the case of Urgent Operations) after the NonConsenting Party receives the appraisal plan, development plan, or authority for expenditure, as applicable. ${ }^{45}$

A provision in a contract that provides or imposes a payment obligation, forfeiture, or other penalty on a party for a breach of the contract that is not a genuine pre-estimate of the damages flowing from the breach may not be enforceable. A sum will be held to be a penalty, as opposed to a genuine pre-estimate of damages, if the amount is "extravagant and unconscionable ... in comparison with the greatest loss that could conceivably be proved to have followed from the breach." 46 John D. McCamus states in The Law of Contracts: "On the other hand, a term that is designed to operate in terrorem by stipulating payment of an amount that exceeds the likely damages caused by breach is characterized as a 'penalty' and held to be unenforceable." ${ }^{47}$

However, it is widely accepted that Independent Operations Penalties are enforceable penalties because they are not imposed for a breach of contract and are not intended to impose a penalty that forces a party to comply with its obligations under a contract for fear of being subject to extreme consequences for non-compliance. A Non-Participating Party has no obligation to participate in an Independent Operation and, therefore, its non-participation is not a breach.

What constitutes a reasonable Independent Operation Penalty has been considered in US case law. In the case of Hamilton v. Texas Oil \& Gas Corp., the Court upheld an Independent Operation Penalty based on the following rationale:

2015 CAPL Operating Procedure, supra note 1, cl 10.07.

AIPN UROA, supra note 1, arts 7.4.C.1, 7.4.C.2.

Ibid, art 7.4.D.

Dunlop Pneumatic Tyre Co v New Garage \& Motor Co (1914), [1915] AC 79 (HL (Eng)) at 87-88

[Dunlop]. The Dunlop case is the classic test that is still quoted today. In addition to affirming the test of "genuine pre-estimate of damage," Lord Dunedin formulated four rules of construction: (1) the clause will be declared a penalty if the sum stipulated is "extravagant and unconscionable in amount [when] in comparison with the greatest loss that could conceivably be proved to have followed from the breach" (ibid at 87); (2) if the contractual obligation is to pay a fixed sum of money by a fixed date and there is default, the obligation to pay a larger sum will be deemed a penalty; (3) there is a presumption that a clause is penal when "a single lump sum is made payable by way of compensation, on the occurrence of one or more or all of several events, some of which may occasion serious and others but trifling damage" (ibid at 87, citing Lord Elphinstone v Mankland Iron and Coal Co (1886), 11 App Cas 332 (HL (Scot)); and (4) "[i]t is no obstacle to the sum stipulated being a genuine pre-estimate of damage, that the consequences of the breach are such as to make precise pre-estimation almost an impossibility" (ibid at $87-88$ ).

47 John D McCamus, The Law of Contracts, 2nd ed (Toronto: Irwin Law, 2012) at 964. 
To declare these provisions void as a penalty would permit non-consenting parties to participate in the venture risk free. Testimony evidenced that such provisions between $200 \%$ and $500 \%$ are standard in the industry. In view of the substantial financial risks suffered by consenting parties and in view of the fact that the percentage is to be paid only from production, we believe the $400 \%$ provision of Section 12 of the [JOA] is valid and enforceable. ${ }^{48}$

In the CAPL operating procedures, the Independent Operation Penalty for nonparticipation in drilling a well in a conventional resource is typically suspension of the NonParticipating Party's entitlement to production from the well until recovery of 500 percent of costs, in the case of an exploratory well, or 300 percent of costs, in the case of a development well. Given that such percentages are quite standard in the western Canadian petroleum and natural gas industry, and are not imposed for breach of contract but are commercial provisions that are voluntarily agreed to, we expect they would not be found to be an unenforceable penalty if challenged in a Canadian court.

Under most JOAs used in Canada, non-participation in an operation that is necessary to prevent termination of a petroleum and natural gas lease results in the Non-Participating Party forfeiting its interest in the title document to the extent that the title document would have terminated if the operation had not been conducted. ${ }^{49}$ It is the opinion of the authors of this article that this provision is not a penalty and would not be subject to the equitable principle of relief from forfeiture because, again, it is not imposed as a result of a breach of contract and, more importantly, is fair because the lease would have expired if the Independent Operation was not conducted.

\section{Challenges With IndePENDENT Operations IN THE UNCONVENTIONAL RESOURCE CONTEXT}

Conventional development projects are often small in scale and not complex, with each well constituting a separate and distinct cost and revenue centre. ${ }^{50}$ As a result, Independent Operations in respect of conventional resources can be conducted on a well-by-well basis and, because each well is a discrete unit, Independent Operations can usually be conducted without impacting other existing or future wells drilled into the same reservoir. Stewart and Cioni have said that a new drilling opportunity in a conventional project can be seen as a kind of side bet "because whether or not the independent operation pays out matters little to the success of the primary wells of the joint venture." ${ }^{51}$ A different, and probably better, way of saying this is that in a conventional project, each decision to drill a well is made independent of a decision to drill other wells in the project. While the results of one well in

$48 \quad$ Hamilton v Texas Oil \& Gas Corp, 648 SW (2d) 316 (Tex Ct App 1982) at 321.

49 Desbarats \& MacDiarmid, supra note 38 at 621.

50 British Columbia Ministry of Natural Gas Development and Minister Responsible for Housing, "Conventional Versus Unconventional Oil and Gas" (Victoria: Ministry of Natural Gas Development and Minister Responsible for Housing), online: <www2.gov.bc.ca/assets/gov/farming-natural-resourcesand-industry/natural-gas-oil/petroleum-geoscience/conventional_versus_unconventional_oil and_gas.pdf $>$. Conventional resources are pools or accumulations of natural resources, including oil and gas. There are a number of mechanisms that can form these accumulations. These include:

1. Structural traps whereby broad folds and/or faults lead to concentrations of hydrocarbons;

2. Dome-like structures related to diapiric rise of underlying sediments;

3. Stratigraphic traps where a change in the rock type creates a barrier; and

4. Multiple combinations of the previous processes (ibid). 
a conventional project may provide information that is helpful in predicting the success of a subsequent well or better techniques to use in another well, a decision whether to drill one well is essentially independent from the decision to drill another well in the project. Likewise, a decision whether to conduct a completion, deepening, or similar operation on a well is independent from a decision with respect to other similar operations on the well. Thus, the drilling of wells and, in many cases, operations in respect of a well that has been drilled, are separate cost and revenue centres for which mutually exclusive, independent decisions can be made on a well-by-well basis and Independent Operations Penalties can be easily calculated on this basis.

Unlike conventional resources, unconventional resources are in most cases not exploited on a well-by-well basis, but rather by continuous, multi-well drilling programs. Careful management of the resource base through cascading or sequenced drilling programs may be necessary in order to maximize the ultimate recovery of petroleum substances that represent a very narrow range of realizable opportunities. Drilling programs, including horizontal length, well patterns, drilling pad placement, and fracturing programs, must be conducted with great care and coordination to allow for the most effective exploitation of the reservoir.

A decision to implement a continuous, multi-well drilling program is usually a decision to drill and complete all of the wells in the program. In a conventional, vertical well drilling program, the parties may pause after a well is drilled to assess it and determine whether and where to drill the next well. In an unconventional resource project developed by continuous multi-well drilling programs (which are typical), the parties often cannot pause when a well in the drilling program has been drilled and tested to assess its results to make a determination whether and when to complete it and whether to drill subsequent wells in the drilling program. In most cases, unlike conventional resources, there is little risk that a well drilled in an unconventional reservoir will encounter sufficient petroleum substances to justify its completion or to justify the drilling of the next well in the program, when taking into account the efficiencies of conducting continuous operations rather than pausing to assess results. Since the entire drilling program (including well completions) is most efficient if the entire program is undertaken, it would be unworkable, and unfair, to permit a party to make decisions on a well-by-well basis, participating in some but not others and deferring its decisions until it has all the information from previous wells, which is the procedure applicable to conventional wells under most JOAs. Thus, in most cases, Independent Operations in respect of an unconventional resource that is developed by continuous, multiwell drilling programs should not permit well-by-well decisions on participation in the drilling of wells to be drilled pursuant to the drilling program and should not permit well-bywell decisions on participation in the completion of wells drilled pursuant to the program.

An Independent Operation should not be permitted if it would adversely affect other operations that have higher priority. For example, an Independent Operation should not be permitted on a producing well, and the drilling of a well as an Independent Operation should not be permitted if it would interfere with a joint operation that has previously been approved or with a mandatory work obligation that the parties are obligated to undertake by law or by the terms of a petroleum and natural gas lease or a production sharing contract. Except for an Independent Operation in respect of a producing well, an Independent Operation in a conventional resource that is developed by vertical wells and that is subject to government regulated well spacing (such as occurs in Canada) is unlikely to interfere with an existing 
well or any other authorized operation. For that reason, CAPL operating procedures do not restrict Independent Operations except with respect to producing wells, wells where there are wellbore integrity, safety, or environmental concerns, and to certain deepening and sidetracking operations.

The authors of this article have heard suggestions that when a multi-well drilling pad is used, it is unworkable to allow a party to participate in some but not all of the wells drilled from the pad and, therefore, the drilling of a well from a multi-well pad as an Independent Operation should not be permitted. Except with respect to wells drilled from a pad pursuant to a continuous, multi-well program, we do not believe this to be true so long as one well drilled from the pad does not impact the other wells. Therefore, we believe that separate decisions on participation in wells drilled from a multi-well drilling pad are feasible. Of course, if the ownership of wells drilled from the pad is not uniform, there will have to be allocations of the costs of constructing and maintaining the pad and the equipment thereon and in respect of the use of the pad and the pad equipment. Moreover, if the Independent Operation Penalty applicable to a well drilled from a multi-well drilling pad includes the relinquishment of rights to propose or participate in the drilling of subsequent wells into the area evaluated or proven-up by such well, a Non-Participating Party would not have the right to propose or participate in wells drilled from the drilling pad into that area.

\section{PERMiSSIBLE INDEPENDENT OPERATIONS IN THE 2015 CAPL OPERATING PROCEDURE AND THE AIPN UROA}

\section{INDEPENDENT OPERATIONS PERMITTED IN THE 2015 CAPL OPERATING PROCEDURE}

The 2015 CAPL Operating Procedure prohibits Independent Operations on an existing well if: (1) except in limited circumstances, the well is a producing well; (2) its wellbore is not in suitable condition for, or would be damaged by, the operation; (3) the operation would pose health, safety, or environmental risks; or (4) the Independent Operation is the deepening or sidetracking of the well below its authorized depth and at least one other party has proposed to complete or recomplete the well in a formation above that depth. ${ }^{52}$ In addition, the 2015 CAPL Operating Procedure prohibits a Non-Participating Party from proposing an Independent Operation on the well before its participation in the well has been reinstated following recovery of the applicable penalty. ${ }^{53}$ The 2015 CAPL Operating Procedure otherwise permits Independent Operations for any operation on or with respect to the joint lands or for the construction, acquisition, installation, modification, or expansion of a production facility. However, under clause 10.02A of the 2015 CAPL Operating Procedure, the right to propose an Independent Operation is "subject to ... any restrictions in the [Head] Agreement on a Non-Participating Party's ability to issue an Operation Notice for certain wells described in a Multiple Well Drilling Program or Multiple Well Completion Program." $" 54$ That qualification reflects the determination by the authors of the 2015 CAPL Operating Procedure that there may be circumstances where it is appropriate to provide for additional restrictions on the rights to undertake Independent Operations in respect of 
unconventional resources, but there is not consensus on the circumstances when such additional restrictions are appropriate or the terms that should be applicable in such circumstances. It is better to custom design these in the Head Agreement as and when appropriate.

The 2015 CAPL Operating Procedure maintains the distinction between exploration and development wells used in prior iterations of the CAPL operating procedure and provides for a procedure at clause 10.05 where a well proposed as an Independent Operation would be, in part, a development well and, in part, an exploratory well. ${ }^{55}$ That concept is not in the AIPN UROA.

Under clause 10.02A of the 2015 CAPL Operating Procedure, an Independent Operation cannot pertain to more than one well or production facility ${ }^{56}$ Moreover, under clause $10.02 \mathrm{~F}$ of the 2015 CAPL Operating Procedure, except in the case of a Title Preserving Well and subject to some other specific exceptions, if an Independent Operation is proposed in respect of a well (other than deepening or sidetracking), and there are other operations being conducted on a well on the joint lands within 3.2 kilometers of the proposed well, a party that received the proposal and is entitled to information from the other operation will be deemed (for purposes of calculating the period within which it must respond to the proposal) to have not received the proposal until it has received all of such information from the other operation. ${ }^{57}$ Both of those provisions are usually incompatible with a multi-well drilling program. As a result, the 2015 CAPL Operating Procedure expressly recognizes that clauses $10.02 \mathrm{~A}$ and $10.02 \mathrm{~F}$ will be subject to provisions in the Head Agreement respecting MultiWell Drilling Programs and Multi-Well Completion Programs, if any. ${ }^{58}$

In addition, clause 8.02 of the 2015 CAPL Operating Procedure provides that "Article 9.00 [Casing Point Election] will not apply to the horizontal leg drilled as part of a ... Horizontal Well" and that clause 10.08 (which addresses Independent Operations on a well that has been drilled) "will apply to completion of a Horizontal Leg, unless the parties have otherwise agreed to the Completion program ... in conjunction with the drilling of the ... Well." 59 This is a concept that was introduced in the 2007 version of the CAPL operating procedure.

\section{INDEPENDENT OPERATIONS PERMITTED IN THE AIPN UROA}

Article 7.1 of the AIPN UROA sets forth the operations that may be proposed as Exclusive Operations. ${ }^{60}$

Under article 7.1.A of the AIPN UROA, no Exclusive Operation (other than the tie-in of Exclusive Operation Facilities with existing production facilities under article 7.10) can be conducted if it would conflict with a previously approved operation. ${ }^{61}$ Under article 7.1.B of 
the AIPN UROA, operations required to fulfill minimum work obligations under the Contract $^{62}$ (Minimum Work Obligations) cannot be proposed as an Exclusive Operation. ${ }^{63}$ There is an alternative to that provision which can be selected which, if selected, prohibits Exclusive Operations (except Deepening, Testing, Completing, Sidetracking, Plugging Back, Recompletions, or Reworking (as such terms are defined in the CAPLs) of wells drilled to satisfy the Minimum Work Obligations) until the Minimum Work Obligations for the current phase of the Contract have been satisfied.

If the first alternative of article 7.1.D of the AIPN UROA is selected, the AIPN UROA will permit any operation that can be conducted as a joint operation to be proposed as an Exclusive Operation except "Minimum Work Obligations, Pilot Projects, Multi-Pad Production Facilities, Development Operations from an approved Multi-well Drilling Pad and Production Operations from an approved Multi-well Drilling Pad." ${ }^{64}$ Those exceptions, other than Minimum Work Obligations, are clearly aimed at unconventional resource development since they are not in the 2012 version of the AIPN operating procedure (which is designed for use with conventional resources and is similar to prior versions of the AIPN operating procedure).

If the second alternative of article 7.1.D in the AIPN UROA is selected, only the operations specified in that article can be conducted as Exclusive Operations. ${ }^{65}$ This alternative permits the parties to include Development Operations from an approved Multi-well Drilling Pad and Production Operations from an approved Multi-well Drilling Pad in the list of permitted Independent Operations, but not Pilot Projects or Multi-Pad Production Facilities. It is also aimed at unconventional resources since those operations are not referred to in the 2012 AIPN operating procedure. ${ }^{66}$

In an AIPN, the "Contract" is the production sharing contact, concession, lease, or other instrument that gives the parties to the JOA the petroleum and natural gas rights that are governed by the AIPN.

AIPN UROA, supra note 1, art 7.1.B.

Ibid, art 7.1.D.

Ibid. The operations specified in the second alternative of article 7.1.D of the AIPN UROA that can be proposed as Exclusive Operations are: the acquisition of G \& G Data; drilling, testing, completing, deepening, sidetracking, plugging back and/or re-completing exploration and appraisal wells; development or production operations from an approved multi-well drilling pad and decommissioning and abandonment operations specifically authorized to be undertaken as Exclusive Operations under article 10 of the AIPN UROA.

66 The AIPN UROA defines a "Multi-Pad Production Facility" as "any equipment or property (other than Hydrocarbons) that: (a) are downstream of the Christmas tree of wells drilled to produce Hydrocarbons; (b) are used in connection with the handling and disposition of Hydrocarbons and other substances produced from the Contract Area (including any separator, dehydration unit, treatment facility, disposal well, injection well, extraction facility, processing facility, gathering system, pipeline, compression facility, or production storage facility); and (c) as determined by the Operating Committee" (ibid, art $1.1)$. 


\title{
E. TIMING OF INDEPENDENT OPERATIONS IN THE 2015 CAPL OPERATING PROCEDURE AND THE AIPN UROA
}

\author{
1. WhEN INDEPENDENT OPERATIONS ARE PERMITTED \\ IN THE 2015 CAPL OPERATING PROCEDURE
}

The 2015 CAPL Operating Procedure provides that a party may, at any time, issue an Operation Notice for an operation on the joint lands. ${ }^{67}$ All parties have the right to elect to participate in such operation, except where the operation is in respect of an Independent Well in which the party did not participate and in which its participation rights have not been reinstated. If less than all parties elect to participate in the proposed operation but the interest is nevertheless fully subscribed, the electing parties may proceed as an Independent Operation under article 10, subject to the exceptions described previously in this article. Consistent with previous CAPL operating procedures, the 2015 CAPL Operating Procedure does not require that the proposal must first be submitted to the parties for approval and rejected prior to an Operation Notice that can lead to an Independent Operation being submitted under clause $10.02 .^{68}$

\section{WHEN INDEPENDENT OPERATIONS ARE PERMITTED}

Under article 7.1.C of the AIPN UROA, an Exclusive Operation may only be proposed if: (1) it has been properly proposed to and voted on by, but not approved by, the operating committee; and (2) the party proposing the Exclusive Operation voted in favour of the operation when the operating committee voted on it. ${ }^{69}$ This concept is not in the CAPL operating procedures because they do not provide for an operating committee.

\section{F. INDEPENDENT OPERATIONS PENALTIES AND \\ REINSTATEMENT RIGHTS IN THE 2015 CAPL OPERATING PROCEDURE AND THE AIPN UROA}

\section{INDEPENDENT OPERATIONS PENALTIES IN THE 2015 CAPL OPERATING PROCEDURE}

The 2015 CAPL Operating Procedure provides for the following penalty for nonparticipation in an Independent Operation: circulation of an operation notice before it is proposed as an Independent Operation is that there are so many agreements and wells that that it is not a feasible requirement given the cycle time of operations. Very different circumstances would apply for a major unconventional development scenario, as that would probably involve an annual forecast mechanism, probably evolving to a work program and budget in a cascading development. The AIPN context is completely different because fewer wells are drilled in international fields and multiple well development plans are often approved. 
- Under clause 10.07A, subject to some exceptions, ${ }^{70}$ “" $[\mathrm{t}]$ he Participating Parties will retain possession of an Independent Well Completed or Recompleted for the production of Petroleum Substances," "71 and all production from those formations through that well until the gross proceeds from the sale of that production equals the total of:

- 100 percent of the lessor's royalty and 100 percent of any overriding royalties, freehold mineral taxes, or other encumbrances in respect of the production borne for the joint account;

- 100 percent of the operating costs of the well and any production facility used in the production, processing, treatment, storage, transmission, or other handling of the production;

- 100 percent of the facility fees incurred for use of a facility in the production, processing, treatment, storage, transmission, or other handling of the production;

- 200 percent of the equipping costs of the well; and

- a multiple of the bona fide drilling and completion costs of the well as a development well or as an exploratory well, each such percentage to be specified when the JOA is executed. The multiple is typically 500 percent for an exploratory well and 300 percent for a development well. ${ }^{72}$

- Clause 10.10 provides that a Non-Participating Party in an Independent Well required to maintain title to an oil and gas lease or portion thereof will permanently forfeit its working interest in the portion of the lease that would have expired if the Independent Operation was not conducted. ${ }^{73}$

- Clause 9.03 provides that, if a party participates in the drilling of a well but not its completion, the completion is considered an Independent Operation as if it were an exploratory well or a development well, as the case may be. However, clause 8.02A states that article 9.00 will not apply to a Horizontal Leg drilled as part of a well proposed initially as a Horizontal Well. Also clause 10.08 (Operations on an Existing Well) will apply to the Completion of that Horizontal Leg unless the parties have agreed to the Completion program in conjunction with the drilling of the well. ${ }^{74}$

2015 CAPL Operating Procedure, supra note 1, cl 10.07A. The exceptions are: (1) the provisions of the Head Agreement in respect of Multiple Well Drilling Programs or Multiple Well Drilling Pads; and (2) clauses 10.06 (wells used for other lands), 10.08 (operations on existing wells), and 10.10 (Title Preserving Wells).

71 Ibid. An "Independent Well" is defined as the portion of a well in which an Independent Operation is conducted (ibid, cl 10.07).

Ibid, cl 10.07A.

Ibid, cl 10.10 .

Ibid, cl 9.03 . 
- Clause $10.08 \mathrm{D}$ provides that the cost recovery provisions of clause 10.07 apply, mutatis mutandis, to the recovery of costs of a deepening, sidetracking, recompletion, reworking, or other downhole operation conducted as an Independent Operation. $^{75}$

Under clause $10.07 \mathrm{C}$, after the Independent Operation Penalty is recovered, the NonParticipating Party is entitled to resume participation in the production and production revenue from the Independent Well. ${ }^{76}$ A Non-Participating Party might choose not to reinstate its participation in the Independent Well if it believes that the future net production revenue from the well will be less than the costs of abandonment of the well and the environmental liabilities associated with the well.

\section{INDEPENDENT OPERATIONS PENALTIES AND REINSTATEMENT RIGHTS IN THE AIPN UROA}

Under article 7.4.B of the AIPN UROA,${ }^{77}$ the Non-Consenting Party in an Exclusive Operation will relinquish the following:

- The right to participate in further operations to drill, deepen, recomplete, rework, sidetrack, or test in the well, or deepened or sidetracked portion of a well, in which the Exclusive Operation was conducted;

- the right to participate in any Commercial Discovery in the Exclusive Area, if any; and

- the right under the Contract to take and dispose of Hydrocarbons produced from the Exclusive Area. $^{78}$

\section{Ibid, cl 10.08D.}

Ibid, cl 10.07C

AIPN UROA, supra note 1, art 7.4.B. The Relinquishment will be subject to Articles 7.6E (completion at shallower depth if impenetrable formations are encountered) and 7.8 (Deepening and Sidetracking of an Independent Well) if those Articles (which are options) are made applicable.

78 The AIPN UROA, ibid, art 1.1, contains the following definitions:

"Commercial Discovery" means a Discovery or Unconventional Resource that is sufficient to entitle the Parties to apply for authorization from the Government to commence exploitation.

"Exclusive Area" means the portion of the Contract Area covered by the Sub-Area in which a well is drilled, Deepened, Recompleted, Reworked or Sidetracked as an Exclusive Operation and the Sub-Areas touching any point or side of the Sub-Area in which such Exclusive Operation is conducted, but excluding such adjacent Sub-Areas that are within any existing Drilling Pad Drainage Area, or in any Sub-Area in which an approved Multi-well Drilling Pad is, or will be, located.

"Sub-Area" means a subdivision of the Contract Area delineated as:

- [Alternative \#1] the [x] kilometer by [x] kilometer grid; or

- Alternative \#2] the prospective development fairways that is/are superimposed on the initial Contract Area as set out in Exhibit B-2.

"Drilling Pad Drainage Area" means:

- [Alternative \#1] the Sub-Areas penetrated by one or more Laterals drilled from a Multi-well Drilling Pad.

- [Alternative \#2] the smallest rectangular portion of the Contract area that encompasses the Total Measured Depth of all Laterals drilled from a Multi-well Drilling Pad.

"Total Measured Depth" means regarding a Horizontal Well, the distance from the surface of the ground to the terminus of the well bore, as measured along the well bore. Each Lateral taken together with the common vertical component is collectively one well bore. 
Article 7.5 of the AIPN UROA provides that a Non-Consenting Party in an Exclusive Operation has the following rights to reinstate the rights it relinquished by not participating in the Exclusive Operation:

- If the Consenting Parties decide to appraise an Exclusive Area, for a period of 30 days (or 48 hours for "Urgent Operational Matters") from receipt of the Appraisal Plan;

- $\quad$ if the Consenting Parties decide to develop an Exclusive Area, for a period of 60 days from receipt of the Development Plan or such lesser period prescribed by the Contract; and

- $\quad$ if the Consenting Parties decide to deepen, complete, sidetrack, plug back, or recomplete an Exclusive Well and such operation was not included in the original proposal for the Exclusive Well, for 30 days (or 48 hours for Urgent Operational Matters) from receipt of the AFE for the further Operation in the Exclusive Area. ${ }^{79}$

If the Non-Consenting Party wishes to reinstate its relinquished rights, it must pay the following amount (referred to in this article as a Reinstatement Payment) to the Consenting Parties: the sum of (1) the Non-Consenting Party's Participating Interest ${ }^{80}$ share of the costs and liabilities incurred in every Exclusive Operation relating to the Discovery or Exclusive Well (as applicable) in which it wishes to reinstate its rights (referred to in this article as the Cost Reimbursement); and (2) an amount (referred to in this article as the Reinstatement Premium) equal to a percentage of the costs and liabilities of each of such Exclusive Operations. ${ }^{81}$ The percentages used to calculate the Reinstatement Premium will vary depending on the nature of the specific Exclusive Operation. They are to be agreed upon by the parties to the JOA when it is executed and will vary from JOA to JOA depending on the nature and risk of the project.

The parties to a CAPL or AIPN operating procedure must establish the Reinstatement Premium when the JOA is executed. Typically, the amount increases as the risk of the operation increases. Typical elections in clause 10.07A(e) of a 2015 CAPL Operating Procedure and the corresponding provision of the earlier CAPL operating procedures are 500 percent of drilling and completion costs for an Independent Operation that involves an exploratory well and 300 percent of drilling and completion costs for an Independent Operation that involves a development well. In addition, 200 percent of equipping costs and 100 percent and operating costs must be recovered. ${ }^{82}$ The 500 percent or 300 percent of

79
80 Ibid, art 7.5 .

80 Under the AIPN UROA, a party's Participating Interest is its interest in the Contract expressed as a percentage.

81 The AIPN UROA requires the parties to select, when the JOA is executed, one of two alternatives for payment of the Cost Reimbursement and the Reinstatement Premium. The first alternative provides that a Non-Consenting Party that exercises its Reinstatement Rights must pay the applicable amount to the Consenting Parties as a lump sum amount. The second alternative provides that the Non-Consenting Party must pay the Cost Reimbursement or the Reinstatement Premium by bearing 100 percent of the subsequent cash calls made on each Consenting Party for joint operations and Exclusive Operations until the Cost Reimbursement or Reinstatement Payment (as applicable) has been paid in full. The parties can select one of the alternatives for payment of the Cost Reimbursement and the other alternative for the payment of the Reinstatement Premium if they wish. 
drilling and completion costs comprises recovery of 100 percent of costs plus a premium of 400 percent or 200 percent of costs, and the 200 percent of equipping costs comprises recovery of 100 percent of costs plus a premium of 100 percent of costs. The amount in excess of actual costs is called the Reinstatement Premium in this article.

Reinstatement Premiums are usually greater under AIPN operating procedures than under CAPL operating procedures, reflecting greater risk and greater upside and perhaps an intention to discourage non-participation. A Reinstatement Premium of 1,000 percent of costs is not uncommon in a conventional AIPN operating procedure for an Exclusive Operation that is the drilling of an Exploration Well.

One of the fundamental differences between the AIPN and CAPL operating procedures is that under CAPL operating procedures, the Participating Party's reward for undertaking the Independent Operation (except in the case of a Title Preserving Well) is limited solely to production from the Independent Well. ${ }^{83}$ Under the AIPN operating procedure, the penalty involves forfeiture (subject to Reinstatement Rights) of a portion of area granted by the Host Government Grant. ${ }^{84}$

The requirement under a CAPL operating procedure that 200 percent of equipping costs and either 300 or 500 percent of drilling and completion costs must be recovered would usually be very high for an unconventional resource. In many cases, such recovery would never occur due to high drilling and completion costs and the production profiles of unconventional wells. ${ }^{85}$

Some JOAs applicable to unconventional resources in Canada (but not a CAPL operating procedure, unless provided for in the Head Agreement) provide that a Non-Participating Party in an Independent Operation that is the drilling of wells from a drilling pad will forfeit its interest in all production from all wells drilled from such drilling pad and, sometimes, from an additional area surrounding the drilling pad. The authors of this article believe that the CAPL is correct in leaving these provisions to be determined by the parties when the JOA is prepared and requiring them to be included in the Head Agreement rather than in the model form operating procedure. This is because what will be suitable Independent Operations Penalties will vary greatly from project to project and will depend on the characteristics and stage of development of the resource when the JOA is executed. ${ }^{86}$

Ibid, cl 10.07A.

AIPN UROA, supra note 1, art 7.4.B.2.

Stewart \& Cioni, supra note 11 at 4,6 .

The draftspersons of the 2015 CAPL Operating Procedure share this view. See Jim MacLean, "The Extreme Operating Procedure Makeover is Complete," The Negotiator (March 2016) 2 at 6-7, online: $<$ www.landman.ca/wp/wp-content/uploads/2016/03/Mar2016_Negotiator.pdf $>$ [MacLean, "Procedure Makeover']. 


\section{G. Other IndePENDENT Operations Provisions OF THE 2015 CAPL Operating Procedure AND THE AIPN UROA}

\section{INDEMNIFICATION OF THE NON-PARTICIPATING PARTIES}

Under article 7.3A of the AIPN UROA, the Consenting Parties in an Exclusive Operation are obligated to bear the entire cost and liability of conducting an Exclusive Operation. ${ }^{87}$ They must also indemnify the Non-Consenting Parties from any damages, losses, costs, and liabilities incurred incident to such Independent Operation, including Consequential Loss and Environmental Loss. ${ }^{88}$ Article 10.3 of the AIPN UROA provides that article 10, which addresses the abandonment and decommissioning of facilities and equipment acquired for or contributed to the Joint Account, will apply, mutatis mutandis, to the decommissioning of facilities and equipment acquired for an Exclusive Operation and abandonment of any Independent Well. ${ }^{89}$ Security for such obligations is rarely addressed. If it is addressed, it is usually ambiguous and possibly unenforceable, with the result that the Non-Participating Parties will have no recourse if they are liable for such liabilities under applicable law or other contracts and the Participating Parties fail to discharge them.

Clause 10.18 of the 2015 CAPL Operating Procedure requires the Participating Parties in an Independent Operation to indemnify the Non-Participating Parties from any damages, losses, costs, and liabilities incurred incident to such Independent Operation, subject to the provisions of the 2015 CAPL Operating Procedure respecting Extraordinary Damages. ${ }^{90} \mathrm{It}$ does not, however, include an obligation to provide security for such obligations in the manner described in the AIPN UROA. Given the life cycle of unconventional operations and the possible magnitude of abandonment and reclamation obligations, specific, enforceable security should be considered..$^{91}$

If the fracking of an Independent Well damages another well that was drilled for the joint account, the Participating Parties in the Independent Well may have liability to the NonParticipating Parties for the damage. This possibility is more acute under the AIPN UROA because article 7.3.A thereof specifically provides that the Consenting Parties must indemnify the Non-Consenting Parties from losses, including Consequential Loss. ${ }^{92}$ Consequential Loss is defined to include reservoir or formation damage and inability to produce, use, or dispose of Hydrocarbons. ${ }^{93}$

Under clause 10.18 of the 2015 CAPL Operating Procedure, the Participating Parties must indemnify the Non-Participating Parties from damages resulting from an Independent


CAPL Operating Procedure expressly states that no provision thereof will make any Party responsible for Extraordinary Damages suffered by any other Party. ${ }^{95}$ Extraordinary Damages

AIPN UROA, supra note 1 , art 7.3A.

Ibid.

Ibid, art 10.3.

2015 CAPL Operating Procedure, supra note 1, cl 10.18.

Ibid, cl 12.01 annotation.

AIPN UROA, supra note 1, art 7.3.A.

Ibid, art 1.1.

Supra note 1, cl 10.18.

Ibid, cl 4.04 . 
is defined in clause 1.01 of the 2015 CAPL Operating Procedure and specifically includes consequential damages, including business interruption, loss of profits, and reservoir or formation damage. ${ }^{96}$

Thus, under the AIPN UROA, a Participating Party may be liable to a Non-Participating Party for damages to a joint well caused by the fracking of an Independent Well to a greater extent than under the 2015 CAPL Operating Procedure.

\section{PROPOSAL PROCESS}

Under the AIPN UROA and the 2015 CAPL Operating Procedure, the party proposing an operation must issue a notice to the other co-owners proposing to undertake the operation as an Independent or Exclusive Operation. ${ }^{97}$ That notice triggers the rights of the other parties to elect to participate in the operation and the imposition of Independent Operations Penalties if they do not.

\section{USE OF JOINT PROPERTY}

The AIPN UROA and the 2015 CAPL Operating Procedure allow the use of joint property and equipment for an Independent Operation, provided that the participating parties indemnify the non-participating parties in respect thereof. ${ }^{98}$

\section{COMPETING PROPOSALS}

Petroleum exploration and development is not an exact science, and opinions on the best course of action to explore, appraise, or develop an unconventional resource will vary. The AIPN UROA and the 2015 CAPL Operating Procedure deal with this issue differently. Under the AIPN UROA, if an Exclusive Operation has been proposed, another party may propose a competing operation within a specified time..$^{99}$ The parties will then vote on the proposals and the operation receiving the most votes will have priority. If there is a tie, the Operator will break the tie. This issue is not specifically addressed in the 2015 CAPL Operating Procedure. Since the 2015 CAPL Operating Procedure does not prohibit the proposal of competing operations, some in the Canadian oil and gas industry are of the view that the first in time proposal receives priority. ${ }^{100}$ Others expect that as between competing proposals, the party who is able to first obtain a surface lease and well licence will have priority for the proposed Independent Operation. ${ }^{101}$

\section{RIGHT TO INFORMATION}

Under clause 10.19 of the 2015 CAPL Operating Procedure, subject to provisions in the Head Agreement "respecting non-participation in a Multiple Well Drilling Program, a Multiple Well Completion Programs or any other well being drilled as part of the

Ibid, $\mathrm{cl} 1.01$.

Ibid, cl 10.02; AIPN UROA, supra note 1, art 7.2.A,

2015 CAPL Operating Procedure, ibid, cl 10.12; AIPN UROA, ibid, art 7.9.

AIPN UROA, ibid, art 7.6.

This has been the experience of the authors of this article.

This is based on advice the authors received from Mr. Jim MacLean. 
development of a Well Pad," 102 a Non-Participant in an Independent Operation is not entitled to access the wellsite of an Independent Well or to receive information from the operation until 150 days after rig release if the operation is the drilling, sidetracking, or deepening of a well. In the case of completion, recompletion, or reworking operation, the later of the rig release date and 90 days after the completion, recompletion, or reworking operation is completed. ${ }^{103}$

Under the AIPN UROA, a Non-Consenting Party is entitled to information from an Exclusive Operation for as long as it has the right to reinstate its participation, ${ }^{104}$ other than an operation to acquire $G \& G$ Data from a non-drilling operation, for which no limit is provided. ${ }^{105}$

\section{G \& G DATA}

Under the AIPN UROA, an operation to acquire G \& G Data can only be conducted as a joint operation under article 3 or as an Exclusive Operation under article 7. Under article 7.4.A of the AIPN, a party that does not participate in an Exclusive Operation to obtain G $\& \mathrm{G}$ Data has the right to receive and use the data by paying its Participating Interest (namely, its interest in the contract) of the costs of acquiring the G \& G Data. ${ }^{106}$

Under clause 10.11 of the 2015 CAPL Operating Procedure, a party may conduct an operation to acquire $\mathrm{G} \& \mathrm{G}$ Data without any obligation to offer the other parties the opportunity to participate in the operation and, in such event, the other parties have no rights to the G \& G Data. ${ }^{107}$ This provision was changed in the 2007 version of the CAPL operating procedure. The 1990 version of the CAPL operating procedure provided that if a party was offered the right to participate in the $\mathrm{G} \& \mathrm{G}$ Data operation (there is no obligation to make such an offer) and declined, it would have the right to acquire a copy of the G \& G Data by paying a 200 percent penalty but would not thereby acquire trading rights.

\section{TIME FOR COMMENCEMENT OF AN INDEPENDENT OPERATION}

Under the AIPN UROA and the 2015 CAPL Operating Procedure, if a party submits notice to conduct an Independent Operation, it has a specific number of days to commence such operation, failing which, its right to conduct the operation terminates and a new notice must be submitted. ${ }^{108}$ Under both the AIPN UROA and the 2015 CAPL Operating Procedure, a proposing party is not obligated to conduct the proposed Independent Operation. 


\section{Tailoring Sole Risk Provisions \\ FOR UNCONVENTIONAL RESOURCES}

\section{A. TeaChings From THE 2015 CAPL OPERATING PROCEDURE AND THE AIPN UROA}

The 2015 CAPL Operating Procedure was designed to offer a change in approach from prior iterations of the CAPL operating procedure that would greatly enhance the functionality and flexibility to accommodate more complex projects. ${ }^{109}$ The 2015 CAPL Operating Procedure offers a more appropriate foundation for unconventional projects without attempting to predict or prescribe detailed project-specific development processes that are more appropriately left for the parties to negotiate for their particular circumstances. This is accomplished by giving the parties the option to make several of the provisions of article 10 (Independent Operations) subject to the terms and conditions of the Head Agreement in respect of multi-well drilling and completion programs and well pads without specifying the mechanisms to deal with them in the context of Independent Operations. The annotations to the 2015 CAPL Operating Procedure state that:

\footnotetext{
These references will mitigate the need for custom changes in the Operating Procedure ... by supplementing a broad potential range of outcomes negotiated specifically for any particular Agreement. It was not feasible to address the topic more specifically, given the lack of consensus on pad development approaches when the 2015 document was created. ${ }^{110}$
}

The authors of the 2015 CAPL Operating Procedure clearly intended that, when it is anticipated that development will be undertaken by multiple well drilling and completion programs and multi-well pad drilling, the parties to the JOA should consider putting provisions in the Head Agreement specifically tailored to the resource and the anticipated development operations. However, if special provisions are not included in the Head Agreement, Independent Operations will be subject to more or less the same concepts as applied to Independent Operations in prior iterations of the CAPL operating procedures. This is not meant as a criticism of the 2015 CAPL Operating Procedure. It would not have been feasible to include Independent Operations provisions specifically tailored to unconventional resources because of lack of consensus in the Canadian petroleum and natural gas industry and because "one size does not fit all" in this context.

The AIPN UROA also contains significant changes from the prior versions of the AIPN model joint operating agreements. For example:

- The AIPN UROA has modified the definition of Commercial Discovery so that, in addition to including a Discovery (which is a conventional resource concept) for which the government has authorized exploitation, it now also includes an Unconventional Resource for which such exploitation has been approved. ${ }^{111}$ 
- The AIPN UROA has introduced the following new concepts: Drilling Pad Drainage Area, Exclusive Area, Horizontal Well, Multi-pad Production Facility, Multi-well Drilling Pad, Sub-Area, and Unconventional Resource. ${ }^{12}$

- The types of operations that can be conducted as Independent Operations as provided in article 7.1.D of the AIPN UROA have been modified to address Pilot Projects, Multi-pad Production Facilities, and Multi-well Drilling Pads. ${ }^{113}$

- The Independent Operations Penalties and Reinstatement Rights, which are provided for in articles 7.4.B and 7.4.C of the 2012 AIPN operating agreement, have been changed in the AIPN UROA by referencing Exclusive Areas and Commercial Discoveries rather than Discoveries. Significantly, the Exclusive Area is the Sub-Area on which the Exclusive Well is located, plus the eight Sub-Areas that surround it. What constitutes a Sub-Area is predetermined when the JOA is executed, presumably based on the applicable unconventional resource concept. ${ }^{114}$

The provisions of the AIPN UROA that relate to unconventional resources are quite different from the 2015 CAPL Operating Procedure. This is because the AIPN UROA specifically provides for alternative provisions that can be selected in the Independent Operations provisions (article 7) so that those provisions can be tailored to the specific unconventional resource. As noted above, the 2015 CAPL Operating Procedure provides that any such tailoring should be deferred to the Head Agreement. Of course, if the parties to an AIPN UROA wish to use provisions different from the alternatives presented in the model form documents, they can provide for them in the Head Agreement. The alternatives provided for in the AIPN UROA are probably suitable for many very large-scale unconventional resource projects likely to be encountered internationally but may be unsuitable for many unconventional resource projects in Canada, particularly smaller scale or partially established resources. As noted above, the authors of the 2015 CAPL Operating Procedure determined that such alternatives should be in the Head Agreement because there is a lack of consensus in the industry on what the alternatives should be and because of the range of different unconventional resource developments.

\section{B. TYPES OF UNCONVENTIONAL OPERATIONS THAT MAY BE "SOLE-RISKED"}

There are two basic principles that form the basis for Independent Operations provisions:

1. An Independent Operation should not be permitted if it is likely to conflict or interfere with previously approved operations (whether joint operations or Independent Operations) or with future joint operations that are likely to be undertaken;

2. Independent Operations Penalties and Reinstatement Rights should balance the following principles: 
(a) The Participating Parties should be entitled to a fair and reasonable portion of the benefits from the Independent Operation; and

(b) The Non-Participating Parties should not be unfairly or unreasonably penalized, having regard to the fact that they jointly own interests in the joint lands.

It should be noted that when applying these principles to a particular JOA, it is necessary to take into account the nature of the unconventional resource and the method that will be used to exploit it. The more that is known about those matters, the easier it will be to construct the Independent Operations provisions. Conversely, if little is known about the resource and the exploitation methods, it may be difficult to agree upon fair and reasonable Independent Operations provisions. In the latter case, the co-owners could agree to generic Independent Operations provisions in the JOA and hope that they can agree to modify them when better information is available. Alternatively, the parties could agree that no Independent Operations will be permitted unless and until the parties have agreed upon the Independent Operations provisions as and when sufficient information is available. As MacLean observes, sole risk provisions in a JOA for unconventional resource development can evolve or adopt different approaches at different times in the project life cycle. ${ }^{115}$

Independent Operations that would interfere or conflict with previously approved operations or operations that are reasonably anticipated to be undertaken in the future should not be permitted. It may be beneficial to include a general statement in the JOA that Independent Operations that could reasonably be expected to conflict or interfere with previously approved operations cannot be proposed or undertaken. However, the vagueness of such a statement could create problems. In addition, or in the alternative, the JOA could list specific Independent Operations that are not permitted. This list may include an operation on an existing producing well, the drilling of a well in the deemed drainage area of an existing well or multi-well drilling pad, or the drilling of a well that would interfere or conflict with the drilling of or operations in respect of a well whose drilling has previously been approved as a joint operation or an Independent Operation. The deemed drainage area or a mechanism for determining it would have to be agreed upon in the JOA when it is executed. In that regard, the Exclusive Area approach used in the AIPN UROA could be adopted to determine the drainage area for existing or approved wells or multi-well drilling pads.

If the parties can agree on initial operations to define the characteristics of the unconventional resource, such as the collection of G \& G Data or the drilling of exploratory wells, the JOA could provide that no Independent Operations can be proposed or conducted until after those initial operations have been completed or until after an outside date, whichever is earlier.

If the unconventional resource will be developed with continuous, multi-well drilling programs, the Independent Operation provisions should probably state that each party can only elect to participate in all or none of the wells drilled pursuant thereto and not in only 
some of them. Similarly, if a party proposes to complete every well in a multi-well drilling program that it proposes, each of the parties should probably be required to participate in the drilling and completion of all or none of the wells. However, in a few situations, it might be feasible to provide that if a continuous, multi-well drilling program is proposed as an Independent Operation, a Non-Proposing Party may elect to participate in some but not all of the wells, provided that the election is made before the program is commenced. Such a provision could give rise to some issues in allocating costs among the various wells, but that issue should not be insurmountable.

A JOA could provide that a co-owner that does not participate in the construction of a multi-well drilling pad has no right to propose or participate in any wells drilled from that pad. In addition, the JOA could provide that, after the drilling pad is constructed and the initial drilling program therefrom is completed, no subsequent wells can be drilled therefrom as an Independent Operation. As discussed above, these restrictions may not be necessary and a drainage area or proved-up area restriction of the type described above may be preferable.

It may be prudent to provide that a multi-well drilling pad that is proposed as an Independent Operation must contain a minimum number of well locations, cannot exceed more than a maximum number of drilling locations or both. The Independent Operation notice could also permit a non-proposing party to elect to acquire an interest in the drilling pad as to only a certain number of the drilling locations.

Given the complexities and implications of continuous, multi-well drilling programs and other unconventional resource operations, it may be a salutary idea to provide, as is done in the AIPN UROA, that Independent Operations cannot be proposed or conducted unless the co-owners have first met and discussed the proposed operations. In addition, the JOA could provide that an Independent Operation cannot be conducted unless co-owners having a minimum aggregate co-ownership have approved it being conducted as an Independent Operation. Of course, when there are only two owners who each own a 50 percent working interest, such a provision is problematic as it will probably prevent all Independent Operations. It would be possible to provide that such a limitation only applies to an Independent Operation that is the drilling of a well or a multi-well drilling program or the construction of a multi-well drilling pad.

In our view, the provisions of the 2015 CAPL Operating Procedure respecting operations to acquire $\mathrm{G} \& \mathrm{G}$ Data and operations that are the completion, recompletion, reworking, deepening, or sidetracking of a well would be appropriate in almost all cases except the completion of wells drilled pursuant to a continuous, multi-well drilling program in which all wells are to be completed.

The JOA could also contain specific provisions dealing with pilot projects. However, in our experience, pilot projects are not common in unconventional resource development in western Canada. 


\section{FAIR AND REASONABLE INDEPENDENT OPERATIONS PenAlties AND Reinstatement Rights}

There is likely little argument that a fair and reasonable Independent Operation Penalty in respect of non-participation in a Title Preserving Well is forfeiture of the NonParticipating Party's entire interest in the oil and gas lease or Host Government Grant that would have expired if the Independent Operation had not been conducted and that there should be no Reinstatement Rights with respect thereto. In addition, however, it may be appropriate to impose Independent Operations Penalties with respect to areas on the joint lands that would not have expired to the extent they are evaluated by a Title Preserving Well or are in its drainage area. ${ }^{116}$

In other cases, a determination of what is fair and reasonable will be quite subjective and will depend upon a combination of the risks and benefits of the Independent Operation. For example, an Independent Operation on an existing well may have relatively small risk and small benefit beyond improving the production from the well. In such cases, it may be fair and reasonable that the Non-Participating Party only relinquishes rights in respect of future production from that well and may reinstate those rights after the Participating Parties have earned a fair and reasonable return on their investment in the Independent Operation having regard to the risk associated therewith and the benefits of the improved production from the well resulting therefrom.

However, an Independent Operation which demonstrates the economic viability of an unconventional resource or a portion thereof that was not previously known to be economically viable should trigger an Operation Penalty that applies to all of the area that is proven to be economically viable and not just the well or wells that were drilled pursuant to the Independent Operation. This would probably require a definition of the area that was evaluated, which could be defined by references to Sub-Areas (predetermined before the JOA is executed), much like the AIPN UROA. There will be different views as to whether Reinstatement Rights should be permitted in respect of these Independent Operations or whether the risks and benefits are so large that it is fairer that the Non-Participating Parties permanently relinquish all of their rights in the area that was proven to be economically viable.

Because of the high costs of drilling horizontal wells and completing them using multistage fracking techniques, in most cases, a Reinstatement Premium of even 200 percent (an aggregate 300 percent penalty when recovery of costs of the operation are included) is unlikely to be recovered. Some alternatives are:

(1) a reduced Reinstatement Premium (after cost recovery) of, say, 100 percent;

(2) a Reinstatement Premium (after cost recovery) equal to a rate of return on the invested capital at an appropriate rate having regard to risk, which would usually be an investment hurdle rate; or

116 See also Jim MacLean, “The CAPL Operating Procedure and Unconventional Resource Projects : Part 1,” The Negotiator (September 2009) 6, online: <landman.ca.wp/wp_content/uploads/2014/10Sept09 layout.pdf $>$. 
(3) conversion of the Non-Participating Party's interest into a gross overriding royalty that is payable only after the Participating Party has recovered the costs of the Independent Operation.

The authors of this article are unaware of any JOAs that have adopted the proposals described in the second alternative and are aware of only a few that utilize the royalty approach described in the third alternative.

\section{ConCLuSION}

Independent Operations provisions are distinct features of most JOAs for the development of petroleum and natural gas rights. While they conflict with the overarching purpose of a JOA to conduct operations jointly, they allow a co-owner willing to conduct an operation independently to do so when the other co-owners are unable or unwilling to participate without forcing them to participate against their will. As a result, Independent Operations provisions in a JOA provide the parties an opportunity to maximize the resource in accordance with the applicable title document to the best commercial advantage in a given period of time.

Independent Operations provisions were developed in the context of conventional resource development. Unique challenges are presented by their use in the context of unconventional resources and the operations, technologies, and development strategies associated therewith. These challenges include Independent Operations for multi-well drilling programs where well-by-well participation elections are unworkable and the risk that Independent Operations may impair the drainage area of an existing horizontal well. The sole risk provisions contained in the 2015 CAPL Operating Procedure and the AIPN UROA address some ways that Independent Operations may be conducted in an unconventional resource development project. As discussed in this article, there are additional ways to draft sole risk provisions.

Custom drafting of sole risk provisions will be required because unconventional development varies from project to project, depending on the nature of the resource, the stage of development, and the parties' understanding of the development process for the resource. This article has outlined some of the considerations for the draftsperson of Independent Operations provisions for unconventional resource development. These considerations focus on the type of Independent Operations that may be permitted and the appropriate penalties for Non-Participating Parties. 